\title{
Sedation for routine gastrointestinal endoscopic procedures: a review on efficacy, safety, efficiency, cost and satisfaction
}

\author{
Otto S. Lin \\ Digestive Disease Institute, Virginia Mason Medical Center, Seattle, WA, USA
}

Most gastrointestinal endoscopic procedures are now performed with sedation. Moderate sedation using benzodiazepines and opioids continue to be widely used, but propofol sedation is becoming more popular because its unique pharmacokinetic properties make endoscopy almost painless, with a very predictable and rapid recovery process. There is controversy as to whether propofol should be administered only by anesthesia professionals (monitored anesthesia care) or whether properly trained non-anesthesia personnel can use propofol safely via the modalities of nurse-administered propofol sedation, computer-assisted propofol sedation or nurse-administered continuous propofol sedation. The deployment of non-anesthesia administered propofol sedation for low-risk procedures allows for optimal allocation of scarce anesthesia resources, which can be more appropriately used for more complex cases. This can address some of the current shortages in anesthesia provider supply, and can potentially reduce overall health care costs without sacrificing sedation quality. This review will discuss efficacy, safety, efficiency, cost and satisfaction issues with various modes of sedation for non-advanced, non-emergent endoscopic procedures, mainly esophagogastroduodenoscopy and colonoscopy. (Intest Res 2017;15:456-466)

Key Words: Colonoscopy; Propofol; Deep sedation; Endoscopy, digestive system; Anesthesia

\section{INTRODUCTION}

In developed countries, the majority of routine, low-risk endoscopic procedures are currently performed with some form of sedation. ${ }^{1}$ Gastrointestinal (GI) endoscopy is an inherently uncomfortable procedure, with the potential for abdominal pain, cramping and bloating during colonoscopy, ${ }^{2}$ and gagging, retching and choking during esophagogastroduodenoscopy (EGD). The use of sedation allows for a more thorough and relaxed procedure, with higher polyp detection rates and procedures completion rates. ${ }^{3}$ A sedated,

Received August 1, 2017. Revised August 3, 2017.

Accepted August 3, 2017. Published online August 29, 2017

Correspondence to Otto S. Lin, Digestive Disease Institute, Virginia Mason Medical Center, 1100 Ninth Avenue, Seattle, WA 98101, USA. Tel: +1-206-

625-7373 (ext. 67694), Fax:+1-206-341-1405, E-mail: Otto.Lin@vmmc.org

Financial support: None. Conflict of interest: Otto S. Lin served as a consultant for SEDASYS Inc. comfortable patient not only enhances endoscopist satisfaction, ${ }^{4}$ but is associated with a higher likelihood of the patient being willing to undergo the procedure again. The American Society of Anesthesiology (ASA) has published definitions for different levels of sedation (Table 1 ); ${ }^{5}$ specifically, at the level of "moderate sedation," the patient maintains ventilatory and cardiovascular function and is able to make purposeful responses to verbal or tactile stimuli, while at "deep sedation," patients cannot be easily aroused but is still able to respond to noxious or insistent stimuli. Airway support may be required for deep sedation. To allow the procedure to proceed smoothly, sedatives are usually dosed to achieve moderate sedation (benzodiazepine and opiate sedation) or deep sedation (monitored anesthesia care with propofol). In a minority of cases, full "general anesthesia" (with intubation of the patient and the use of anesthetic agents such as nitrous oxide or ketamine) is required because of patient characteristics or procedural complexity. Since full general

\footnotetext{
๑ Copyright 2017. Korean Association for the Study of Intestinal Diseases. All rights reserved.

This is an Open Access article distributed under the terms of the Creative Commons Attribution Non-Commercial License (http://creativecommons.org/licenses/by-nc/4.0)

which permits unrestricted non-commercial use, distribution, and reproduction in any medium, provided the original work is properly cited.
} 
Table 1. Definition of American Society of Anesthesiologists Levels of Sedation and Anesthesia ${ }^{5}$

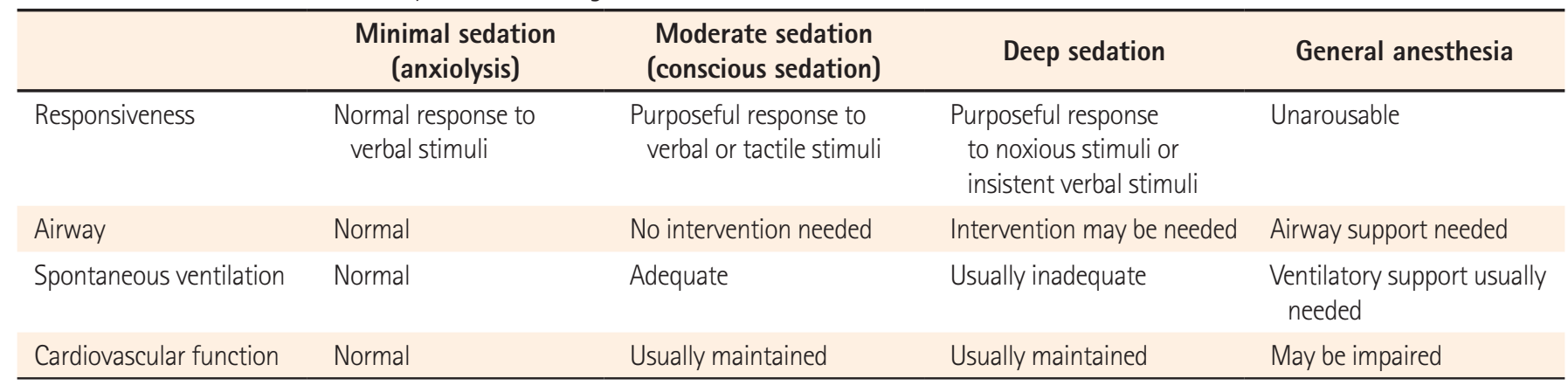

Table 2. Properties of Commonly Used Sedative Agents for Gastrointestinal Endoscopy

\begin{tabular}{ccccccc}
\hline Agent & Onset of action $(\mathrm{min})$ & Peak effect $(\mathbf{m i n})$ & Duration of effect $(\mathbf{m i n})$ & Metabolism & Excretion & Reversal agent \\
\hline Midazolam & $1.0-2.5$ & $3.0-4.0$ & $15.0-80.0$ & Hepatic & Renal & Flumazenil \\
Fentanyl & $1.0-2.0$ & $3.0-5.0$ & $30.0-60.0$ & Hepatic & Renal & Naloxone \\
Propofol & $0.5-1.0$ & $1.0-2.0$ & $4.0-8.0$ & Hepatic & Renal & None \\
\hline
\end{tabular}

anesthesia is not commonly used for routine GI endoscopy, it will not be discussed further in this review.

\section{NON-SEDATED ENDOSCOPY}

Although sedation for endoscopy is becoming widespread, there is still interest in non-sedated endoscopy, even in countries like the United States where almost all GI procedures are performed with sedation. Non-sedated endoscopy offers several potential advantages-lower cost, wider availability, less risk, higher efficiency and decreased post-procedural impairment, allowing for patients to drive or return to work immediately afterwards. There continue to be attempts to develop unsedated EGD using ultrathin transnasal endoscopes, ${ }^{6}$ and unsedated colonoscopy using water immersion techniques. ${ }^{7}$ Motivated patients can successfully undergo unsedated endoscopy, ${ }^{8}$ but the vast majority of patients in developed countries prefer and demand sedation, and the overall trend in GI endoscopy is moving towards more potent, not less potent, forms of sedation..$^{9,10}$

\section{MODERATE SEDATION WITH SEDATIVES, HYPNOTICS AND OPIOIDS}

Initial forms of sedation for GI endoscopy involved moderate sedation using such agents as midazolam, diazepam, pethidine, fentanyl, remifentanil and/or meperidine. Midazolam and diazepam are intravenous benzodiazepines, with powerful sedative, anxiolytic, hypnotic and amnestic effects. Fentanyl, remifentanil and meperidine are intravenous opioid analgesics, with only minimal sedative effects. Typically, moderate sedation is induced by a combination of a benzodiazepine sedative and an opioid analgesic, which have complementary and synergistic effects with each other. Midazolam and fentanyl (MF) have now become the most commonly used moderate sedation agents in the United States, ${ }^{11}$ and many other countries. ${ }^{12}$ Even though some studies reported similar efficacy for midazolam and diazepam, ${ }^{13}$ midazolam is now usually favored over diazepam because of its faster onset of action and better safety profile, ${ }^{14,15}$ while fentanyl has now supplanted meperidine because the former is associated with more rapid onset and clearance, with less nausea. ${ }^{16,17}$ Midazolam is a water-soluble compound prepared in an acidic solution. After introduction into the bloodstream, it reconfigures to a lipophilic structure at physiological $\mathrm{pH}$, rapidly diffusing across the blood-brain barrier into the CNS. The usual total dose for GI endoscopy is 2 to $10 \mathrm{mg}$. Fentanyl, a synthetic opioid agonist with powerful analgesic but only mild sedative properties, is highly lipid soluble and 80 times more potent than morphine. The usual total dose is 50 to $200 \mu \mathrm{g}$. Both agents have a relatively fast onset of action when given intravenously and a short duration of effect (Table 2). Effective reversal agents, naloxone for opioids and flumazenil for benzodiazepines, are readily available. In addition to MF, ancillary agents such as diphenhydramine or droperidol are sometimes used. These agents potentiate the actions of the primary benzodiazepine/opioid regimen, and may be needed for patients who are unusually 
difficult to sedate. The use of droperidol has been limited by its cardiac risks, especially in patients with a history of prolonged QT intervals or electrolyte abnormalities.

Monitoring during sedated endoscopy typically involves assessment of the electrocardiogram (EKG) pattern, blood pressure, pulse oximetry and patient responsiveness; ${ }^{17}$ in many units, capnography is also used, particularly with propofol sedation. Experimental methods such as bispectral index monitoring, a form of electroencephalography, are not widely available as yet.

MF sedation has been found to be effective for routine GI endoscopy. ${ }^{18}$ The safety profile for MF compares quite favorably to that of propofol. Studies have shown that the cardiopulmonary complication rates with MF sedation are generally low, between $0.05 \%$ to $0.10 \%$ for EGDs and colonoscopies ${ }^{17}$ A recent meta-analysis of 27 studies (many of them randomized controlled trials) found that propofol was associated with similar risks of hypoxia (OR, 0.82; 95\% CI, 0.63-1.07), and hypotension (OR, 0.92; 95\% CI, 0.64-1.32) as MF or other traditional sedative agents; for non-advanced procedures, propofol was slightly less likely to cause complications (OR, 0.61; 95\% CI, 0.38-0.99). ${ }^{19}$

\section{MONITORED ANESTHESIA CARE}

The administration of propofol by anesthesia professionals in order to induce deep sedation in unintubated patients is termed "monitored anesthesia care (MAC)" and is one of the most common sedation methods for GI procedures in North America and Europe. Propofol (2,6-diisopropyl phenol) is a short-acting agent with sedative, amnestic and hypnotic properties. It is not an analgesic, but has synergistic effects when given with opioids or benzodiazepines. The target entity is the type A $\gamma$-aminobutyric acid receptor. A typical preparation consists of a $1 \%$ solution, prepared in a mixture of soybean oil, glycerol and egg lecithin, hence it is contraindicated in patients with soy or egg allergy. Propofol, a highly lipophilic compound, is $98 \%$ plasma-protein bound, and is metabolized in the liver by conjugation to glucuronide sulfate to produce water-soluble metabolites excreted by the kidneys. The time from injection to onset of sedation is 30 to 60 seconds, and its duration of effect is 4 to 8 minutes, although its duration of peak effect is considerably shorter (often 1-2 minutes). Its pharmacokinetics do not change in patients with renal or liver failure (Table 2). Because it reduces cardiac output and systemic vascular resistance, it often causes hypotension, while its sedative effects can lead to hypoventilation. Propofol can also cause pain at the injec- tion site, but it is rare for phlebitis to occur.

\section{Effectiveness and Safety Data}

Propofol does not have any known reversal agent, but its extremely short half-life enhances its safety profile considerably. Propofol sedation is associated with relatively good cognitive function in the recovery period, ${ }^{20,21}$ and driving and psychomotor skills recover rapidly, ${ }^{22}$ in contrast to MF sedation. ${ }^{23}$ There have been numerous randomized controlled trials comparing propofol against MF sedation for GI procedures; these data have been summarized in several metaanalyses. Generally, the studies show that propofol is extremely effective at inducing adequate procedural sedation, with high procedural success rates, rapid recovery times and low complication rates. One of the earliest meta-analyses combined data from 12 studies, concluding that propofol for colonoscopy had lower odds of cardiopulmonary complications compared with traditional agents, but for other procedures, the complication risks were similar. ${ }^{24}$ A subsequent meta-analysis of 36 randomized studies showed that compared with MF, propofol expeditiously induced deeper sedation, with high patient satisfaction, and faster and more predictable recovery. ${ }^{18}$ Another meta-analysis that included 22 randomized controlled trials found that propofol was associated with better patient cooperation, shorter recovery and discharge times, higher post-sedation recovery scores and better sedation. ${ }^{25}$ Finally, a meta-analysis of 5 studies on propofol sedation for EGDs in cirrhotic patients showed that propofol led to more rapid sedation and recovery than MF, but the risk of sedation-related side effects did not differ significantly. ${ }^{26}$

\section{Prevalence of Use}

In the United States, where the vast majority of propofol sedation is currently administered by anesthesia professionals, the use of propofol has been fraught with controversy, primarily around the issues of reimbursement and privileging. Over the span of a decade, there has been a 3- to 4-fold increase in the prevalence of anesthesia involvement in routine outpatient endoscopic procedures on low-risk patients, with propofol sedation rates going from 14\% in 2003 to $48 \%$ in 2013 for Medicare patients, and from 14\% in 2003 to $53 \%$ in 2013 for privately insured patients. ${ }^{9,10,27,28}$ Canada has also seen analogous increases. ${ }^{29}$ This has led to significant increases in anesthesia costs for GI endoscopy. ${ }^{30,31}$ Against the current background of national concern about burgeoning 
health care costs, there is evidence that a large proportion of MAC use is medically unnecessary because they involve low-risk procedures that can presumably be performed with moderate sedation using MF or other traditional agents. Furthermore, there are dramatic regional variations in the use of MAC (with the highest rates in areas like New York and Florida), which further supports the notion that much of MAC use is discretionary and redundant. ${ }^{4,32}$

\section{Problems}

The use of anesthesiologist-administered propofol for lowrisk endoscopies is estimated to cost the U.S. health care system an additional $\$ 3.2$ billion (USD) over a period of 10 years. ${ }^{31}$ Although it is somewhat difficult to define "discretionary" anesthesia care with exactitude, ${ }^{33}$ there are widespread concerns that these substantial anesthesia costs are not justified by any improvement in clinical outcomes. ${ }^{34-37}$ Firstly, the use of MAC does not increase the adenoma or polyp detection rate during colonoscopy ${ }^{30,38,39}$ Furthermore, anesthesia-administered propofol sedation may not necessarily be safer than non-anesthesiologist administered MF sedation. Although the use of MAC does not seem to be associated with higher perforation rates, ${ }^{40,41}$ studies looking specifically at force application during colonoscopy found that axial and radial forces tend to be stronger because the patient is more heavily sedated. ${ }^{42}$ In fact, available data either show similar complication rates, ${ }^{25,32,43}$ or higher complication rates with MAC compared with MF sedation. ${ }^{44-46}$ Since none of these studies were randomized, there are legitimate concerns about selection bias, but it is clear that currently available data do not support the notion that anesthesiaadministered propofol is safer than MF sedation. ${ }^{35,36}$

\section{NURSE ADMINISTERED PROPOFOL SEDATION}

Because of these issues with MAC, there have been attempts to investigate nurse-administered propofol sedation (NAPS). ${ }^{47}$ The NAPS dosing protocol varies between centers and countries. In the United States, specially trained nurses typically administer small boluses of propofol at frequent intervals to achieve moderate sedation. In most cases, an initial bolus of 30 to $50 \mathrm{mg}$ is given through a rapidly running intravenous line, followed by boluses of 10 to $20 \mathrm{mg}$ every 30 to 60 seconds. ${ }^{48}$ The use of NAPS instead of MAC for low-risk patients undergoing routine GI procedures seems to represent "low lying fruit" for cost savings and better resource allocation, ${ }^{49}$ but NAPS has remained one of the most controversial aspects of the GI field ${ }^{34,35}$ European and American GI guidelines endorse the use of NAPS for low-risk GI procedures, provided that practitioners undergo proper training. ${ }^{50-52}$ However, these guidelines are at odds with those issued by the ASA, which states that clinicians who use propofol "should be qualified to rescue patients from any level of sedation including general anesthesia." ${ }^{n 3}$

\section{Effectiveness and Safety Data}

Numerous studies from Europe and America have shown NAPS to be feasible and safe, as long as it is performed on appropriately selected patients. ${ }^{54-59}$ Contraindications to NAPS include the presence of significant comorbidities (ASA class 3 or above), severe sleep apnea, morbid obesity, gastric outlet obstruction, gastroparesis and achalasia; patients undergoing advanced complex endoscopic procedures may also be unsuitable for NAPS. ${ }^{48}$ Direct comparisons have shown that NAPS is associated with higher patient satisfaction scores and shorter recovery times compared with MF sedation. ${ }^{58}$ Randomized controlled studies show that NAPS is associated with fewer adverse events and higher satisfaction scores than MAC. ${ }^{60}$ Generally, NAPS seems to be more easily used for colonoscopy than EGD, with a lower risk of having to resort to mask ventilation. ${ }^{59,61}$ An exhaustive review of worldwide safety data involving 646,080 NAPS procedures reported only 11 emergent endotracheal intubations, no permanent neurological injuries and 4 deaths; only $0.1 \%$ of patients required transient mask ventilation. ${ }^{55}$

\section{Regulatory and Financial Obstacles}

NAPS is used extensively in several European countries, including Germany, Sweden, and Switzerland. ${ }^{50,62}$ Payment models seem to have a marked impact on whether anesthesia-administered propofol or NAPS is used; in countries where separate anesthesia service fees are charged (such as France), anesthesia-administered propofol is the dominant model, whereas in other countries NAPS is more popular. ${ }^{63}$ In the United States, NAPS is rarely used. ${ }^{64}$ In addition to financial issues, there are other barriers to its use in the United States, including the U.S. Food and Drug Administration labeling for propofol (which specifies that propofol must be administered by personnel trained in anesthesia), policies of the U.S. Center for Medical Services (the government entity that administers Medicare) on deep sedation, insurance regulations, hospital credentialing rules, and medicolegal concerns. ${ }^{64,65}$ Many U.S. institutions that previously performed 
many cases with NAPS, such as the University of Indiana, have now abandoned its use because of insurmountable regulatory and medicolegal obstacles. ${ }^{64}$

\section{PATIENT CONTROLLED SEDATION}

Patient controlled sedation (PCS) is analogous to the patient-controlled analgesia used in hospitals, where patients can control their own dosage of pain medications. PCS has been looked at in several studies and found to be effective compared against MAC ${ }^{66}$ and conventional MF-type sedation. ${ }^{67-69}$ However, PCS is not widely used because most patients are reluctant to take charge of their own sedation.

\section{COMPUTER-ASSISTED PROPOFOL SEDATION}

The SEDASYS ${ }^{\circledR}$ System (Ethicon Endo-Surgery, Inc., Cincinnati, OH, USA) was approved in the United States in 2013 for providing moderate sedation for ASA class 1 and 2 patients undergoing routine EGD and colonoscopy. Despite considerable media attention, there still seem to be some misconceptions about this technology. SEDASYS ${ }^{\circledR}$ is not a "robotic anesthesiologist." It is a system with built-in safeguards to allow trained non-anesthesiologist physicians onlabel access to propofol. Also, SEDASYS ${ }^{\circledR}$ is not a "closedloop" system. Depending on patient vital signs, the system may restrict, suspend, decrease or stop the propofol infusion, but any increase in drug delivery must be initiated by the clinician. Finally, SEDASYS ${ }^{\circledR}$ is not a "target controlled" system and does not control delivery based on the propofol concentration in the plasma or at the site of drug effect.

\section{Mechanics}

Computer-assisted propofol sedation (CAPS) allows nonanesthesiologists to administer $1 \%$ propofol as a continuous infusion after a premedication dose of fentanyl of 25 to 100 $\mu \mathrm{g}$. The initial infusion rate is determined by the endoscopist and can range from 25 to $75 \mu \mathrm{g} / \mathrm{kg} / \mathrm{min}$. To achieve a suitable level of sedation, the endoscopist can titrate the maintenance infusion rate upwards or downwards during the procedure. A bolus dose of up to $0.25 \mathrm{mg} / \mathrm{kg}$ can also be given.

The CAPS system continuously monitors capnography, oxygen saturation, EKG and blood pressure. In addition, the CAPS system periodically assesses patient alertness by automated response monitoring. With automated response monitoring, patients grip a plastic hand device during the procedure, and are periodically prompted by voice and vibration prompts from the CAPS system to squeeze the device. Longer lag times between the prompt and the squeeze are interpreted as a deeper level of sedation. The initial maintenance rate cannot be more than $75 \mu \mathrm{g} / \mathrm{kg} / \mathrm{min}$, each rate increase cannot be more than $50 \mu \mathrm{g} / \mathrm{kg} / \mathrm{min}$ and the overall maximum infusion rate is set at $200 \mu \mathrm{g} / \mathrm{kg} / \mathrm{min}$. To prevent a stacking effect, there is a 180 -second lockout period after each infusion rate increase, and a 90-second lockout after each bolus. Finally, hypoventilation, oxygen desaturation or lack of responsiveness will prevent further rate increases, and, if severe enough, can lead the CAPS system to discontinue the propofol infusion. In response to significant hypoxia, the CAPS system will increase supplemental oxygen delivery to the patient and trigger visual and auditory alarms to alert the provider team. To use CAPS, an anesthesia professional must be immediately available in the same building for assistance as needed.

\section{Clinical Trial Data}

A pilot study involving 48 patients ${ }^{70}$ was followed by a large, non-blinded multicenter randomized controlled trial, ${ }^{71}$ in which 1,000 healthy adults undergoing colonoscopy or EGD were randomized to CAPS or MF sedation. The area under the curve for oxygen desaturation (a composite measure of the frequency, severity and duration of hypoxic episodes) was significantly lower for the CAPS group. Furthermore, patient and endoscopist satisfaction were greater for CAPS, and CAPS subjects recovered much faster than the MF controls. The overall incidence of complications was $5.8 \%$ for CAPS versus $8.7 \%$ for MF. The only serious sedationrelated adverse event occurred in a control patient who required transient mask ventilation.

\section{Real World Clinical Data}

As the only center in the United States to introduce CAPS for large scale, routine clinical use, we assessed the efficacy, safety, efficiency and satisfaction associated with the use of CAPS in a real-world environment. In our first study ${ }^{72}$ CAPS was utilized to sedate 55 EGDs and 173 colonoscopy patients; concurrently, 75 EGDs and 223 colonoscopies were performed with MF sedation on controls. Just like in the trials, endoscopists were more satisfied with CAPS than MF sedation. Also, patients were more satisfied with CAPS with regard to recovery parameters (Table 3$)^{72,73}$ Procedural success rates and colonoscopic polyp detection rates were similarly high in both groups. Procedure times were not different, 
Table 3. Procedural Success Rate, Colonoscopic Polyp Detection Rates, Procedure Times, Recovery Times, Patient and Endoscopist Satisfaction Scores, and Adverse Events ${ }^{72}$

\begin{tabular}{|c|c|c|c|}
\hline Prevalence & $\begin{array}{c}\text { CAPS } \\
(n=244)\end{array}$ & $\begin{array}{c}\text { MF } \\
(n=328)\end{array}$ & $P$-value \\
\hline \multicolumn{4}{|l|}{ Procedural success rate $(\%)$} \\
\hline EGD & 98.2 & 98.7 & 0.958 \\
\hline Colonoscopy & 98.9 & 98.8 & 0.592 \\
\hline Polyp detection rate (\%) & 54.5 & 59.3 & 0.666 \\
\hline \multicolumn{4}{|l|}{ Patient satisfaction (PSSI scores) } \\
\hline EGD sedation adequacy & 92.9 & 91.7 & 0.855 \\
\hline Colonoscopy sedation adequacy & 94.8 & 89.9 & $0.002^{2}$ \\
\hline EGD recovery process & 92.3 & 92.4 & 0.795 \\
\hline Colonoscopy recovery process & 96.0 & 90.1 & $<0.001^{\mathrm{a}}$ \\
\hline EGD global satisfaction & 94.8 & 95.4 & 0.704 \\
\hline Colonoscopy global satisfaction & 97.0 & 93.7 & $<0.001^{\mathrm{a}}$ \\
\hline \multicolumn{4}{|l|}{ Endoscopist satisfaction (CSSI scores) } \\
\hline EGD recovery process & 89.1 & 69.2 & $<0.001^{\mathrm{a}}$ \\
\hline Colonoscopy recovery process & 95.9 & 75.4 & $<0.001^{\mathrm{a}}$ \\
\hline EGD global satisfaction & 79.9 & 78.6 & 0.555 \\
\hline Colonoscopy global satisfaction & 94.1 & 83.8 & $<0.001^{\mathrm{a}}$ \\
\hline \multicolumn{4}{|l|}{ Procedure time (min) } \\
\hline EGD & 12.5 & 11.3 & 0.183 \\
\hline Colonoscopy & 25.0 & 24.8 & 0.891 \\
\hline Recovery time (min) & 26.4 & 39.1 & $<0.001^{\mathrm{a}}$ \\
\hline Overall adverse events (\%) & $4.1^{\mathrm{b}, \mathrm{c}}$ & $4.0^{d}$ & 0.910 \\
\hline
\end{tabular}

Patient satisfaction was measured using a validated 19-item questionnaire, the Patient Sedation Satisfaction Index (PSSI), ${ }^{73}$ administered immediately prior to the patient's departure from our unit. Endoscopist satisfaction was measured using another validated 21item questionnaire, the Clinician Sedation Satisfaction Index (CSSI), administered shortly after each procedure. Scores can range from 0 to 100 , with higher scores denoting higher satisfaction.

a Signifies statistically significant $P$-values.

Including 4 cases of agitation due to undersedation during EGDs, and 2 cases of desaturation, 3 of hypotension and 1 of agitation from undersedation during colonoscopies.

'In terms of serious adverse events, 1 patient required brief mask ventilation for desaturation during colonoscopy. Another patient had presented with bloody diarrhea and was diagnosed with ischemic colitis during the colonoscopy, dying 14 days after the procedure from sepsis and multi-organ failure (this death was not felt to be caused by the colonoscopy).

${ }^{d}$ Including 3 cases of agitation due to undersedation during EGDs, 2 cases of desaturation, 3 of hypotension and 1 of agitation from undersedation during colonoscopies, and 1 case of hypotension and 2 of agitation due to undersedation.

CAPS, computer-assisted propofol sedation; MF, midazolam fentanyl; EGD, esophagogastroduodenoscopy. but recovery times were much faster for CAPS than MF Adverse events were uncommon in both groups. For CAPS, 1 patient required brief mask ventilation, 4 experienced mild hypotension or desaturation, and 5 suffered agitation due to undersedation. For MF, 5 patients had mild hypotension or desaturation, and 8 suffered agitation. There were no instances in which a "code" had to be called or an anesthesia professional had to be summoned to assist with sedationrelated complications.

We subsequently reported our 1-year experience with CAPS for colonoscopy on a much larger cohort. ${ }^{74}$ In this study, 2,677 colonoscopies were performed with CAPS, compared against 2,286 historical MF controls. For CAPS, the procedural completion rate was high (98.8\%) and similar to that of controls (99.0\%, $P=0.526$ ). Polyp detection rates and large polyp detection rates were also similar to that of controls (53.4\% vs. $50.1 \%$ and $8.2 \%$ vs. $8.2 \%$ respectively, $P>0.01$ for both). Mean procedure times were slightly shorter for the CAPS group than the controls (22.2 minutes vs. $22.8 \mathrm{~min}-$ utes, $P<0.001)$. Again, recovery times were markedly shorter (31.0 minutes vs. 45.6 minutes, $P<0.001$ ). In the CAPS group, there were $20(0.7 \%)$ cases of mild oxygen desaturation, 21 $(0.8 \%)$ cases of asymptomatic hypotension, $4(0.1 \%)$ cases of agitation due to undersedation, and $2(<0.1 \%)$ cases of desaturation requiring transient mask ventilation. In a separate study on a 1-year cohort of 926 patients undergoing EGD with CAPS, ${ }^{75}$ procedural success rates were again similar to that of MF controls. Procedure times were also similar, but recovery time was markedly shorter. There were 11 (1.2\%) cases of mild desaturation, $15(1.6 \%)$ cases of agitation due to undersedation, and $1(0.1 \%)$ case of mild hypotension. In addition, there were $6(0.6 \%)$ patients with desaturation that required transient mask ventilation. Aside from one case of delayed fatality from ischemic colitis believed to be unrelated to sedation, none of the EGD or colonoscopy subjects suffered any severe adverse event such as emergent intubation, hospitalization, permanent injury or death.

Overall, CAPS was found to be a safe, effective and efficient means of providing sedation for EGD and colonoscopy in relatively healthy patients. Even though the rapid recovery associated with propofol does not negate limitations such as the prohibition against driving after the procedure, it has a major impact on patient satisfaction, post-procedural education and endoscopy unit flow. ${ }^{76,77}$ In addition, recovery room staffing was made more efficient, with overtime hours reduced by $32 \%$, resulting in over $\$ 14,000$ (USD) in savings per month despite increased procedure volumes. ${ }^{78}$ 


\section{SEDASYS ${ }^{\circledR}$ : Closure and Financial Challenges}

At the end of 2016, the manufacturer of SEDASYS ${ }^{\circledR}$ closed down its CAPS division due to the company's inability to project profitability from this technology ${ }^{79}$ Between 2014 and 2016, reportedly only 10 or fewer CAPS systems were sold in the United States. Despite excellent safety and effectiveness outcomes, financial factors proved to be decisive in the failure of this product. Currently, there are strong financial incentives to use anesthesia-administered propofol, ${ }^{9,35,63}$ because anesthesia charges represent a major revenue source for many endoscopy practices in the United States. In many cases, insurance plans will cover anesthesia charges for endoscopy. In fact, Medicare covers anesthesia costs for screening colonoscopies without any deductibles. This policy was intended to increase the uptake of colon cancer screening, despite studies showing that anesthesia use is not associated with any increase in screening rates, ${ }^{80}$ but will increase costs. ${ }^{81}$ In situations where insurance coverage for anesthesia is denied, patients are charged directly. These factors limit the number of GI providers willing to invest in a CAPS system, since they would have to absorb the sedation costs. In theory, the endoscopy practice would derive other benefits from CAPS such as decreased recovery times, reduced recovery room staffing needs, and increased patient satisfaction. However, these potential benefits are usually not enough to persuade endoscopy units to invest in the considerable upfront costs of a CAPS system.

\section{NURSE ADMINISTERED PROPOFOL CONTINUOUS INFUSION SEDATION}

In our unit, the universal enthusiasm for non-anesthesiologist-administered propofol sedation on the part of nurses, doctors and patients motivated us to develop so-called nurse-administered propofol continuous infusion sedation (NAPCIS), which is a propofol delivery method that replicates the capabilities of CAPS by using programmable intravenous fluid infusion pumps commonly available in the hospital (Alaris ${ }^{\circledR}$ pump module; Becton Dickinson, Franklin Lakes, NJ, USA). Patient selection criteria for NAPCIS are similar to those for CAPS; thus, NAPCIS is reserved for relatively healthy patients undergoing non-advanced, elective, outpatient GI procedures.

\section{Mechanics}

In NAPS, the propofol is typically delivered as small, frequent intermittent boluses. Given our experience with CAPS, we reasoned that propofol administered as a continuous infusion may be more effective and safer than a bolus strategy, ${ }^{82}$ even though previous experiences at other centers with continuous infusion propofol had been disappointing. ${ }^{83}$ NAPCIS delivers propofol as a continuous infusion after an optional loading dose of fentanyl, using a dosing and safety protocol identical to that in CAPS. Towards the end of 2016, we transitioned seamlessly from CAPS to NAPCIS.

\section{Preliminary Data}

In 2017, we presented preliminary data on NAPCIS. ${ }^{84}$ Between December 2016 and January 2017, 490 patients underwent outpatient EGD or colonoscopy with NAPCIS at our center. These subjects were compared against 2 historical control groups, consisting of similar low-risk patients who had undergone procedures with CAPS (228) or MF sedation (298). The procedural success rate with NAPCIS was high and similar to that seen in CAPS and MF. NAPCIS procedure times were significantly shorter compared against CAPS and MF; more importantly, recovery times were shorter than CAPS and much shorter than MF (Table 4) ${ }^{84}$ For NAPCIS, there were 2 cases of transient desaturation that required brief mask ventilation. There were no other serious complications such as intubation, having to call a "code," unantici-

Table 4. Outcomes for Procedures Performed with NAPCIS, CAPS, and MF Sedation ${ }^{84}$

\begin{tabular}{|c|c|c|c|c|c|}
\hline & NAPCIS $(n=490)$ & CAPS $(n=228)$ & $P$-value ${ }^{a}$ & MF $(n=298)$ & $P$-value \\
\hline Procedural success rate (\%) & 98.6 & 98.7 & 0.85 & 98.8 & 0.78 \\
\hline Mean upper endoscopy procedure time (min) & 8.6 & 12.5 & $<0.01^{\mathrm{c}}$ & 11.3 & $<0.01^{\mathrm{c}}$ \\
\hline Mean colonoscopy procedure time (min) & 22.0 & 25.0 & $<0.01^{\mathrm{c}}$ & 24.8 & $<0.01^{\mathrm{c}}$ \\
\hline Mean recovery time (min) & 23.2 & 26.4 & $<0.01^{\mathrm{c}}$ & 39.1 & $<0.01^{c}$ \\
\hline
\end{tabular}

${ }^{a} P$-value, nurse-administered propofol continuous infusion sedation (NAPCIS) versus computer-assisted propofol sedation (CAPS) comparison.

${ }^{b} P$-value, NAPCIS versus midazolam fentanyl (MF) comparison.

'Signifies statistically significant $P$-values. 
pated hospitalization, permanent injury or death. These low complication rates were similar to those seen with CAPS (only one case of mask ventilation) and MF (no mask ventilation). Most endoscopists and nurses found NAPCIS easier to perform than CAPS, and much superior to MF.

We have now performed NAPCIS on over 5,000 patients, with excellent completion rates ( $>99 \%)$, very low complication rates, no serious complications and high patient and endoscopist satisfaction. We believe that NAPCIS is a promising method to deliver non-anesthesiologist administered propofol sedation, but it is important to note that NAPCIS is not designed for medically unstable patients or highly complex endoscopic procedures. Since there is an absolute ceiling for the propofol infusion rate $(200 \mu \mathrm{g} / \mathrm{kg} / \mathrm{min})$, NAPCIS may not offer adequate sedation for patients who are very tolerant to sedatives. These more challenging scenarios will still require the expertise of an anesthesia professional delivering general anesthesia or MAC. ${ }^{85}$

\section{BUNDLED PAYMENTS}

Many of the factors that pose as obstacles to the adoption of NAPS and CAPS also apply to NAPCIS as well. These include various regulatory, political and medicolegal issues. However, the most important obstacles are probably financial. At least in the United States, the current insurance coverage system makes MAC more financially attractive than NAPS or NAPCIS for providers, ${ }^{37}$ thus explaining the dramatic increase in MAC use while the use of non-anesthesia propofol sedation remains uncommon. ${ }^{10}$ However, with the anticipated advent of bundled payments for screening and surveillance colonoscopy, ${ }^{86-88}$ non-anesthesiologist administered propofol sedation may become more attractive. Colonoscopy is an ideal candidate for bundling because it is a well-defined episode of care with little variability; elective EGD may also be an appropriate candidate. Bundling would involve payment of a prenegotiated amount that would cover the costs of the index procedure, any sedation or anesthesia, any pathologic analysis of biopsies, any repeat procedures (within a short period) performed because of poor bowel preparation or complications such as postpolypectomy bleed, and any secondary examinations such as virtual colonoscopy in cases of incomplete colonoscopy. Other methods of cost control, such as reference pricing, are also being investigated. ${ }^{89,90}$ There is a delicate balance between cost control and maintenance of quality, making this an area of active research.

\section{CONCLUSIONS}

In conclusion, endoscopic sedation continues to evolve. In developed countries, it is expected that patients will demand more potent forms of sedation in the future, and thus propofol is likely to assume greater importance. Anesthesiaadministered propofol sedation is effective and safe, but is limited by access and cost. CAPS is effective but unfortunately no longer available; nevertheless, non-anesthesia administered propofol sedation continues to be possible in the form of NAPS and NAPCIS. NAPS is already widely used in many European countries. The introduction of bundled payments may eventually make NAPS or NAPCIS the modality of choice in the United States. The roles played by these modalities will be determined by ongoing research on their efficacy and safety, as well by regulatory, medicolegal and financial factors.

\section{REFERENCES}

1. Standards of Practice Committee of the American Society for Gastrointestinal Endoscopy, Lichtenstein DR, Jagannath S, et al. Sedation and anesthesia in GI endoscopy. Gastrointest Endosc 2008;68:815-826.

2. Ghanouni A, Plumb A, Hewitson P, Nickerson C, Rees CJ, von Wagner C. Patients' experience of colonoscopy in the English Bowel Cancer Screening Programme. Endoscopy 2016;48:232240.

3. Radaelli F, Meucci G, Sgroi G, Minoli G; Italian Association of Hospital Gastroenterologists (AIGO). Technical performance of colonoscopy: the key role of sedation/analgesia and other quality indicators. Am J Gastroenterol 2008;103:1122-1130.

4. Cohen LB, Wecsler JS, Gaetano JN, et al. Endoscopic sedation in the United States: results from a nationwide survey. Am J Gastroenterol 2006;101:967-974.

5. Gross JB, Bachenberg KL, Benumof JL, et al. Practice guidelines for the perioperative management of patients with obstructive sleep apnea: a report by the American Society of Anesthesiologists Task Force on Perioperative Management of patients with obstructive sleep apnea. Anesthesiology 2006;104:1081-1093.

6. Sami SS, Subramanian V, Ortiz-Fernández-Sordo J, et al. Performance characteristics of unsedated ultrathin video endoscopy in the assessment of the upper GI tract: systematic review and meta-analysis. Gastrointest Endosc 2015;82:782-792.

7. Leung FW. Water-aided colonoscopy. Gastroenterol Clin North Am 2013;42:507-519. 
8. Rex DK, Imperiale TF, Portish V. Patients willing to try colonoscopy without sedation: associated clinical factors and results of a randomized controlled trial. Gastrointest Endosc 1999;49:554559.

9. Liu H, Waxman DA, Main R, Mattke S. Utilization of anesthesia services during outpatient endoscopies and colonoscopies and associated spending in 2003-2009. JAMA 2012;307:1178-1184.

10. Predmore Z, Nie X, Main R, Mattke S, Liu H. Anesthesia service use during outpatient gastroenterology procedures continued to increase from 2010 to 2013 and potentially discretionary spending remained high. Am J Gastroenterol 2017;112:297-302.

11. Childers RE, Williams JL, Sonnenberg A. Practice patterns of sedation for colonoscopy. Gastrointest Endosc 2015;82:503-511.

12. Riphaus A, Macias-Gomez C, Devière J, Dumonceau JM. Propofol, the preferred sedation for screening colonoscopy, is underused. Results of an international survey. Dig Liver Dis 2012;44:389-392.

13. Zakko SF, Seifert HA, Gross JB. A comparison of midazolam and diazepam for conscious sedation during colonoscopy in a prospective double-blind study. Gastrointest Endosc 1999;49:684689.

14. Lee MG, Hanna W, Harding H. Sedation for upper gastrointestinal endoscopy: a comparative study of midazolam and diazepam. Gastrointest Endosc 1989;35:82-84.

15. Cole SG, Brozinsky S, Isenberg JI. Midazolam, a new more potent benzodiazepine, compared with diazepam: a randomized, double-blind study of preendoscopic sedatives. Gastrointest Endosc 1983;29:219-222.

16. Horn E, Nesbit SA. Pharmacology and pharmacokinetics of sedatives and analgesics. Gastrointest Endosc Clin N Am 2004;14:247-268.

17. Waring JP, Baron TH, Hirota WK, et al. Guidelines for conscious sedation and monitoring during gastrointestinal endoscopy. Gastrointest Endosc 2003;58:317-322.

18. McQuaid KR, Laine L. A systematic review and meta-analysis of randomized, controlled trials of moderate sedation for routine endoscopic procedures. Gastrointest Endosc 2008;67:910-923.

19. Wadhwa V, Issa D, Garg S, Lopez R, Sanaka MR, Vargo JJ. Similar risk of cardiopulmonary adverse events between propofol and traditional anesthesia for gastrointestinal endoscopy: a systematic review and meta-analysis. Clin Gastroenterol Hepatol 2017;15:194-206.

20. Ulmer BJ, Hansen JJ, Overley CA, et al. Propofol versus midazolam/fentanyl for outpatient colonoscopy: administration by nurses supervised by endoscopists. Clin Gastroenterol Hepatol 2003;1:425-432.

21. Watkins TJ, Bonds RL, Hodges K, Goettle BB, Dobson DA, Maye JP. Evaluation of postprocedure cognitive function using 3 distinct standard sedation regimens for endoscopic procedures. AANA J 2014;82:133-139.
22. Horiuchi A, Nakayama Y, Fujii H, Katsuyama Y, Ohmori S, Tanaka N. Psychomotor recovery and blood propofol level in colonoscopy when using propofol sedation. Gastrointest Endosc 2012;75:506-512.

23. Willey J, Vargo JJ, Connor JT, Dumot JA, Conwell DL, Zuccaro G. Quantitative assessment of psychomotor recovery after sedation and analgesia for outpatient EGD. Gastrointest Endosc 2002;56:810-816.

24. Qadeer MA, Vargo JJ, Khandwala F, Lopez R, Zuccaro G. Propofol versus traditional sedative agents for gastrointestinal endoscopy: a meta-analysis. Clin Gastroenterol Hepatol 2005;3:10491056.

25. Wang D, Chen C, Chen J, et al. The use of propofol as a sedative agent in gastrointestinal endoscopy: a meta-analysis. PLoS One 2013;8:e53311. doi: 10.1371/journal.pone.0053311.

26. Tsai HC, Lin YC, Ko CL, et al. Propofol versus midazolam for upper gastrointestinal endoscopy in cirrhotic patients: a meta-analysis of randomized controlled trials. PLoS One 2015;10:e0117585. doi: 10.1371/journal.pone.0117585.

27. Inadomi JM, Gunnarsson CL, Rizzo JA, Fang H. Projected increased growth rate of anesthesia professional-delivered sedation for colonoscopy and EGD in the United States: 2009 to 2015. Gastrointest Endosc 2010;72:580-586.

28. Khiani VS, Soulos P, Gancayco J, Gross CP. Anesthesiologist involvement in screening colonoscopy: temporal trends and cost implications in the Medicare population. Clin Gastroenterol Hepatol 2012;10:58-64.e1.

29. Alharbi O, Rabeneck L, Paszat LF, et al. A population-based analysis of outpatient colonoscopy in adults assisted by an anesthesiologist. Anesthesiology 2009;111:734-740.

30. Inadomi JM. Editorial: endoscopic sedation: who, which, when? Am J Gastroenterol 2017;112:303-305.

31. Hassan C, Rex DK, Cooper GS, Benamouzig R. Endoscopistdirected propofol administration versus anesthesiologist assistance for colorectal cancer screening: a cost-effectiveness analysis. Endoscopy 2012;44:456-464.

32. Dominitz JA, Baldwin LM, Green P, Kreuter WI, Ko CW. Regional variation in anesthesia assistance during outpatient colonoscopy is not associated with differences in polyp detection or complication rates. Gastroenterology 2013;144:298-306.

33. Fleisher LA. Assessing the value of "discretionary" clinical care: the case of anesthesia services for endoscopy. JAMA 2012;307:1200-1201.

34. Agrawal D, Rockey DC. Propofol for screening colonoscopy in low-risk patients: are we paying too much? JAMA Intern Med 2013;173:1836-1838.

35. Rex DK, Vargo JJ. Anesthetist-directed sedation for colonoscopy: a safe haven or siren's song? Gastroenterology 2016;150:801803. 
36. Repici A, Hassan C. The endoscopist, the anesthesiologists, and safety in GI endoscopy. Gastrointest Endosc 2017;85:109-111.

37. Rex DK. The science and politics of propofol. Am J Gastroenterol 2004;99:2080-2083.

38. Metwally M, Agresti N, Hale WB, et al. Conscious or unconscious: the impact of sedation choice on colon adenoma detection. World J Gastroenterol 2011;17:3912-3915.

39. Paspatis GA, Tribonias G, Manolaraki MM, et al. Deep sedation compared with moderate sedation in polyp detection during colonoscopy: a randomized controlled trial. Colorectal Dis 2011;13:e137-e144. doi: 10.1111/j.1463-1318.2011.02555.x

40. Adeyemo A, Bannazadeh M, Riggs T, Shellnut J, Barkel D, Wasvary $H$. Does sedation type affect colonoscopy perforation rates? Dis Colon Rectum 2014;57:110-114.

41. Hsieh TK, Hung L, Kang FC, Lan KM, Poon PW, So EC. Anesthesia does not increase the rate of bowel perforation during colonoscopy: a retrospective study. Acta Anaesthesiol Taiwan 2009;47:162-166.

42. Korman LY, Haddad NG, Metz DC, et al. Effect of propofol anesthesia on force application during colonoscopy. Gastrointest Endosc 2014;79:657-662.

43. Lubarsky DA, Guercio JR, Hanna JW, et al. The impact of anesthesia providers on major morbidity following screening colonoscopies. J Multidiscip Healthc 2015;8:255-270.

44. Wernli KJ, Brenner AT, Rutter CM, Inadomi JM. Risks associated with anesthesia services during colonoscopy. Gastroenterology 2016;150:888-894.

45. Cooper GS, Kou TD, Rex DK. Complications following colonoscopy with anesthesia assistance: a population-based analysis. JAMA Intern Med 2013;173:551-556.

46. Vargo JJ, Niklewski PJ, Williams JL, Martin JF, Faigel DO. Patient safety during sedation by anesthesia professionals during routine upper endoscopy and colonoscopy: an analysis of 1.38 million procedures. Gastrointest Endosc 2017;85:101-108.

47. Vargo JJ. Big NAPS, little NAPS, mixed NAPS, computerized NAPS: what is your flavor of propofol? Gastrointest Endosc 2007;66:457-459.

48. Rex DK, Overley CA, Walker J. Registered nurse-administered propofol sedation for upper endoscopy and colonoscopy: why? when? how? Rev Gastroenterol Disord 2003;3:70-80.

49. Orkin FK, Duncan PG. Substrate for healthcare reform: anesthesia's low-lying fruit. Anesthesiology 2009;111:697-698.

50. Dumonceau JM, Riphaus A, Beilenhoff U, et al. European curriculum for sedation training in gastrointestinal endoscopy: position statement of the European Society of Gastrointestinal Endoscopy (ESGE) and European Society of Gastroenterology and Endoscopy Nurses and Associates (ESGENA). Endoscopy 2013;45:496-504.
51. Dumonceau JM, Riphaus A, Schreiber F, et al. Non-anesthesiologist administration of propofol for gastrointestinal endoscopy: European Society of Gastrointestinal Endoscopy, European Society of Gastroenterology and Endoscopy Nurses and Associates guideline. Updated June 2015. Endoscopy 2015;47:11751189.

52. Vargo JJ, Cohen LB, Rex DK, et al. Position statement: nonanesthesiologist administration of propofol for GI endoscopy. Gastroenterology 2009;137:2161-2167.

53. American Society of Anesthesiologists Task Force on Sedation and Analgesia by Non-Anesthesiologists. Practice guidelines for sedation and analgesia by non-anesthesiologists. Anesthesiology 2002;96:1004-1017.

54. Sieg A; bng-Study-Group, Beck S, et al. Safety analysis of endoscopist-directed propofol sedation: a prospective, national multicenter study of 24,441 patients in German outpatient practices. J Gastroenterol Hepatol 2014;29:517-523.

55. Rex DK, Deenadayalu VP, Eid E, et al. Endoscopist-directed administration of propofol: a worldwide safety experience. Gastroenterology 2009;137:1229-1237.

56. Rex DK, Heuss LT, Walker JA, Qi R. Trained registered nurses/ endoscopy teams can administer propofol safely for endoscopy. Gastroenterology 2005;129:1384-1391.

57. Sathananthan D, Young E, Nind G, et al. Assessing the safety of physician-directed nurse-administered propofol sedation in low-risk patients undergoing endoscopy and colonoscopy. Endosc Int Open 2017;5:E110-E115.

58. Sipe BW, Rex DK, Latinovich D, et al. Propofol versus midazolam/meperidine for outpatient colonoscopy: administration by nurses supervised by endoscopists. Gastrointest Endosc 2002;55:815-825.

59. Walker JA, McIntyre RD, Schleinitz PF, et al. Nurse-administered propofol sedation without anesthesia specialists in 9152 endoscopic cases in an ambulatory surgery center. Am J Gastroenterol 2003;98:1744-1750.

60. Poincloux L, Laquière A, Bazin JE, et al. A randomized controlled trial of endoscopist vs. anaesthetist-administered sedation for colonoscopy. Dig Liver Dis 2011;43:553-558.

61. Rex DK, Overley C, Kinser K, et al. Safety of propofol administered by registered nurses with gastroenterologist supervision in 2000 endoscopic cases. Am J Gastroenterol 2002;97:11591163.

62. Riphaus A. NAPS in 2016: why not everywhere? Endosc Int Open 2017;5:E222-E223.

63. Dumonceau JM. Nonanesthesiologist administration of propofol: it's all about money. Endoscopy 2012;44:453-455.

64. Rex DK. Effect of the centers for Medicare \& Medicaid Services policy about deep sedation on use of propofol. Ann Intern Med 2011;154:622-626. 
65. Aisenberg J, Cohen LB, Piorkowski JD Jr. Propofol use under the direction of trained gastroenterologists: an analysis of the medicolegal implications. Am J Gastroenterol 2007;102:707-713.

66. Mandel JE, Lichtenstein GR, Metz DC, Ginsberg GG, Kochman ML. A prospective, randomized, comparative trial evaluating respiratory depression during patient-controlled versus anesthesiologist-administered propofol-remifentanil sedation for elective colonoscopy. Gastrointest Endosc 2010;72:112-117.

67. Külling D, Orlandi M, Inauen W. Propofol sedation during endoscopic procedures: how much staff and monitoring are necessary? Gastrointest Endosc 2007;66:443-449.

68. Roseveare C, Seavell C, Patel P, et al. Patient-controlled sedation and analgesia, using propofol and alfentanil, during colonoscopy: a prospective randomized controlled trial. Endoscopy 1998;30:768-773.

69. Liu SY, Poon CM, Leung TL, et al. Nurse-administered propofolalfentanil sedation using a patient-controlled analgesia pump compared with opioid-benzodiazepine sedation for outpatient colonoscopy. Endoscopy 2009;41:522-528.

70. Pambianco DJ, Whitten CJ, Moerman A, Struys MM, Martin JF. An assessment of computer-assisted personalized sedation: a sedation delivery system to administer propofol for gastrointestinal endoscopy. Gastrointest Endosc 2008;68:542-547.

71. Pambianco DJ, Vargo JJ, Pruitt RE, Hardi R, Martin JF. Computer-assisted personalized sedation for upper endoscopy and colonoscopy: a comparative, multicenter randomized study. Gastrointest Endosc 2011;73:765-772.

72. Lin OS, Kozarek RA, Tombs D, et al. The first US clinical experience with computer-assisted propofol sedation: a retrospective observational comparative study on efficacy, safety, efficiency, and endoscopist and patient satisfaction [published online ahead of print March 17, 2017]. Anesth Analg. doi:10.1213/ ANE.0000000000001898.

73. Vargo J, Howard K, Petrillo J, Scott J, Revicki DA. Development and validation of the patient and clinician sedation satisfaction index for colonoscopy and upper endoscopy. Clin Gastroenterol Hepatol 2009; 7:156-162.

74. Lin OS, La Selva D, Kozarek RA, et al. One year experience with computer-assisted propofol sedation for colonoscopy. World J Gastroenterol 2017;23:2964-2971.

75. Lin OS, La Selva D, Tombs D, Kozarek RA, Ross AS. One year experience with computer-assisted propofol sedation for esophagogastroduodenoscopy. Gastrointest Endosc 2016; 83(5 Suppl): AB534-AB535.

76. Horiuchi A, Graham DY. Special topics in procedural sedation: clinical challenges and psychomotor recovery. Gastrointest Endosc 2014;80:404-409.
77. Vargo JJ, Bramley T, Meyer K, Nightengale B. Practice efficiency and economics: the case for rapid recovery sedation agents for colonoscopy in a screening population. J Clin Gastroenterol 2007;41:591-598.

78. Koch J, Tombs D, Lin OS, et al. Economic impact of computer assisted propofol sedation. Gastroenterology 2016; 150(4 Suppl 1):S101.

79. Singh PM, Borle A, Goudra BG. Use of computer-assisted drug therapy outside the operating room. Curr Opin Anaesthesiol 2016;29:506-511.

80. Hirshman S, Mattke S, Liu H. Anesthesia service use and the uptake of screening colonoscopies. Med Care 2017;55:623-628.

81. Liu H, Mattke S, Predmore ZS. Medicare coverage of anesthesia services during screening colonoscopies for patients at low risk of sedation-related complications. JAMA Intern Med 2015;175:1848-1850.

82. Martínez JF, Aparicio JR, Compañy L, et al. Safety of continuous propofol sedation for endoscopic procedures in elderly patients. Rev Esp Enferm Dig 2011;103:76-82.

83. Riphaus A, Geist C, Schrader K, Martchenko K, Wehrmann T. Intermittent manually controlled versus continuous infusion of propofol for deep sedation during interventional endoscopy: a prospective randomized trial. Scand J Gastroenterol 2012;47:1078-1085.

84. Lin OS, Kozarek RA, Tombs D, Ross AS. Nurse administered propofol continuous infusion sedation (NAPCIS): a new paradigm for GI procedure sedation. Gastroenterology 2017;152(5 Suppl 1):S1314.

85. Goudra BG, Singh PM. SEDASYS, sedation, and the unknown. J Clin Anesth 2014;26:334-336.

86. Brill JV, Jain R, Margolis PS, et al. A bundled payment framework for colonoscopy performed for colorectal cancer screening or surveillance. Gastroenterology 2014;146:849-853.e9.

87. Patel K, Presser E, George M, McClellan M. Shifting away from fee-for-service: alternative approaches to payment in gastroenterology. Clin Gastroenterol Hepatol 2016;14:497-506.

88. Dorn SD. The road ahead 3.0: changing payments, changing practice. Clin Gastroenterol Hepatol 2016;14:785-789.

89. Lieberman D, Allen J. New approaches to controlling health care costs: bending the cost curve for colonoscopy. JAMA Intern Med 2015;175:1789-1791.

90. Robinson JC, Brown TT, Whaley C, Finlayson E. Association of reference payment for colonoscopy with consumer choices, insurer spending, and procedural complications. JAMA Intern Med 2015;175:1783-1789. 